www.jmscr.igmpublication.org

Index Copernicus Value: 79.54

ISSN (e)-2347-176x ISSN (p) 2455-0450

crossrefDOI: https://dx.doi.org/10.18535/jmscr/v7i2.148

\title{
Intravenous Ascorbic Acid (Vitamin C) Dose Needed in Critically Ill Patients with Sepsis and Septic Shock Post Cardiac Surgeries
}

\author{
Authors \\ Yousry El Said Rizk, ${ }^{1}$ Ahmed Hamdy Abd Al Rahman, ${ }^{2}$ Mohammed Ahmed El \\ Gazzar, ${ }^{1}$ Mahmoud Muhammed Abd Al Hafeith Jaber \\ ${ }^{1}$ Cardiothoracic Surgery Head of Critical Care Department Faculty of Medicine Benha University \\ ${ }^{2}$ Anesthesia \& Intensive Care Faculty of medicine Benha University
}

\begin{abstract}
Introduction: Sepsis, a syndrome of physiologic, pathologic, and biochemical abnormalities induced by infection, is a major public health concern, accounting for more than \$20 billion (5.2\%) of total US hospital costs in 2011.

Sepsis is a life-threatening systemic inflammatory response that can result in multi-organ dysfunction and intractable hypotension. In critically ill patients, severe sepsis and septic shock are known as the main causes of mortality. Adequate fluid resuscitation, infection control, cardiovascular and respiratory supports are recommended for the management of severe sepsis and septic shock.

Effects of ascorbic acid on hemodynamic parameters were evaluated in nonsurgical critically ill patients in limited previous studies. High-dose ascorbic acid in patients with burn injury decreased fluid and vasopressors' requirements. Also, in patients with severe sepsis, high-dose intravenous ascorbic acid improved hemodynamic parameters. ${ }^{[2]}$

Benha University Hospitals in the academic year of 2017. Patients were divided into 3 groups:

- Group 1: Control (conventional management; IV fluids + antibiotics + vasopressors

- Group 2: 3 grams/day.

- Group 3: 6 grams/day.

Conclusion: We suggested that the early use of intravenous vitamin $C$ may prove to be effective in preventing progressive organ dysfunction including acute kidney injury and reducing the mortality of patients with severe sepsis and septic shock. This inexpensive and readily available intervention has the potential to reduce the global mortality from sepsis.
\end{abstract}

\section{Introduction}

Sepsis, a syndrome of physiologic, pathologic, and biochemical abnormalities induced by infection, is a major public health concern, accounting for more than $\$ 20$ billion $(5.2 \%)$ of total US hospital costs in 2011. ${ }^{[1]}$
Sepsis is a life-threatening systemic inflammatory response that can result in multi-organ dysfunction and intractable hypotension. In critically ill patients, severe sepsis and septic shock are known as the main causes of mortality. Adequate fluid resuscitation, infection control, cardiovascular and respiratory supports are 
recommended for the management of severe sepsis and septic shock. ${ }^{[2]}$

Septic shock usually does not response to intravenous fluid resuscitation and most patients need a vasopressor drug administration. Concomitant vasodilatation and reduced vascular response to the vasopressors have been detected in septic shock. Several mechanisms such as adrenal insufficiency, endothelial damage, oxidative stress, and depletion of catecholamine storage are proposed for vascular hyporesponsiveness to vasopressors in critically ill patients with septic shock. $^{[3]}$

Ascorbic acid (Vitamin C) is an essential nutrient with potent antioxidant properties. Ascorbic acid deficiency defined as serum ascorbic acid level $<23 \mu \mathrm{mol} / \mathrm{L}$ has been reported in critically ill patients with acute respiratory infections and sepsis. High-dose ascorbic acid improved edema and respiratory function in critically ill patients with severe burn injury and decreased organ failure and duration of Intensive Care Unit (ICU) stay in patients after major surgery. ${ }^{[2]}$

Many important issues must be addressed before vitamin $\mathrm{C}$ can be incorporated in sepsis treatment protocols. The most effective dose and the best time for administration remain to be determined. Under normal physiological conditions, 100 to $300 \mathrm{mg}$ vitamin C per day is sufficient to reach adequate plasma concentrations. In contrast, up to $3 \mathrm{~g}$ daily is needed to restore normal plasma concentrations in critically ill patients. ${ }^{[4]}$

Toxicity of high-dose vitamin $\mathrm{C}$ has not been reported in published clinical trials. However, theoretical concerns exist that a high vitamin $\mathrm{C}$ intake might cause pro-oxidant effects, excess iron absorption, vitamin B12 deficiency, or allergic reactions. $^{[5]}$

Despite these robust experimental benefits, few studies have evaluated the effect of vitamin C supplementation in human sepsis. Fowler et al. studied intravenous infusion of 50 or 200 $\mathrm{mg} / \mathrm{kg} /$ day ascorbic acid every 6 hours for 4 days in patients with severe sepsis. As compared with placebo, patients receiving ascorbic acid exhibited less inflammation and prompt reduction of organ failure. Zabet et al. compared infusion of 25 $\mathrm{mg} / \mathrm{kg}$ ascorbic acid every 6 hours for 72 hours with placebo in a small cohort of patients with septic shock who required norepinephrine treatment. $^{[6]}$

\section{Aim of the work \\ Objective*}

The aim of this work is investigate the most effective and least harmful dose of vitamin $\mathrm{C}$ in patients with sepsis and septic shock by dividing patient into different groups with daily assessment by SOFA Score.

\section{Value}

Evaluate the benefit of several doses of vitamin C to come up with the optimum efficacy, avoiding toxicity and decrease mortality rate of sepsis and septic shock patients. ${ }^{[6]}$

\section{Patients and Methods}

* This prospective observational and dose ranging study consisted of ninety patients who were admitted to the Critical Care Department, Benha University Hospitals post cardiac surgeries in the academic year of 2017.

* Cardiac surgeries performed were 37 Mitral valve replacement, 31 Aortic valve replacement, 8 Aortic Aneurysm and 4 Aortic Dissection.

\section{Patients were divided into 3 groups:}

- Group 1: Control (conventional management; IV fluids + antibiotics + vasopressors).

- Group 2: 3 grams/day.

- Group 3: 6 grams/day.

\section{Inclusion criteria:}

Patients with septic shock (within 72 hours of the performed surgery or development of septic shock during their ICU stay).

Patients included in the study were fulfilling the following criteria on admission:

\section{A: Two or more of the following parameters:}

- Temperature $>38^{\circ} \mathrm{C}$ or $<36^{\circ} \mathrm{C}$.

- $\mathrm{HR}>90 \mathrm{bpm}$. 
- $\mathrm{RR}>30 / \mathrm{min}$ with $\mathrm{PaCo} 2<32 \mathrm{mmHg}$.

- TLC $>12000 / \mathrm{dL}$ or $<4000 / \mathrm{dL}$ or $>10 \%$ staff cells.

B: Hypotension was defined as (systolic pressure $<90 \mathrm{mmHg}$, or reduced from baseline by $>40$ $\mathrm{mmHg}$ ) without response to fluid resuscitation and in the absence of other causes of hypotention.

C: An identified source of infection.

Refractory circulatory failure was defined as a persistent or growing metabolic acidosis despite adequate vasoactive support over an observation period of 6-12 hours, and was judged to be present if there was a base excess below $5 \mathrm{mmol} / \mathrm{l}$ at the end of this period (Bone et al., 1992).

\section{Exclusion criteria:}

- Age younger than 18 years or older than 75 years old.

- Pregnancy or breastfeeding.

- Requirement for immediate surgery within the treatment protocol timeframe.

\section{Methods:}

All patients were subjected to the following:

1. Full history taking.

2. Complete clinical examination.

3. Routine laboratory investigation :

- Complete blood picture and white blood cell differential on admission.

- Blood Urine Nitrogen (BUN) (mg/dl) and creatinine $(\mathrm{mg} / \mathrm{dl})$.

- Aspartate aminotransferase (AST), Alanine aminiotransferase (ALT) and serum bilirubin $(\mathrm{mg} / \mathrm{dl})$.

- Prothrombin Time (PT), Partial Thromboplastin Time (PTT) and International Normalized Ratio (INR).

- Random Blood Sugar (RBS) (mg/dl), serum sodium $(\mathrm{Na})$ and potassium $(\mathrm{K})$.

- Arterial Blood Gases (ABG).

4. Daily assessment of patients with Sequential Organ Failure Assessment (SOFA) score.

\section{Results}

The present study was constructed to investigate the efficacy and the optimum dose of vitamin $\mathrm{C}$ in patients with sepsis and septic shock after cardiac surgeries associated with decreased morbidity, mortality and ICU stay. Ninety patients developed septic shock were studied; 50 males and 40 females.

A statistical comparison between the three groups as regard age and sex reveals $\mathrm{N}$ difference as regard these demographic data.

Table (1): Demographic characteristics of the studied groups

\begin{tabular}{|c|c|c|c|c|}
\hline & $\begin{array}{l}\text { Group I } \\
(\mathbf{n}=\mathbf{3 0})\end{array}$ & $\begin{array}{c}\text { Group II } \\
(\mathbf{n}=\mathbf{3 0})\end{array}$ & $\begin{array}{l}\text { Control } \\
(\mathbf{n}=\mathbf{3 0})\end{array}$ & $\mathbf{p}$ \\
\hline Age (years) & & & & \\
\hline Mean \pm SD & $59.4 \pm 8.1$ & $58.4 \pm 7.9$ & $59.3 \pm 8.3$ & 0.87 \\
\hline Range & 45-80 & 45-80 & 45-80 & (NS) \\
\hline \multicolumn{5}{|l|}{ Gender } \\
\hline Male & 16 & 17 & 17 & 0.95 \\
\hline Female & 14 & 13 & 13 & (NS) \\
\hline
\end{tabular}

A statistical comparison between the three groups as regard body mass index reveals $\mathrm{N}$ difference.

Table (2): Body mass index in the studied groups

\begin{tabular}{|c|c|c|c|c|}
\hline BMI & $\begin{array}{c}\text { Group I } \\
(\mathbf{n}=\mathbf{3 0})\end{array}$ & $\begin{array}{c}\text { Group II } \\
(\mathbf{n}=\mathbf{3 0})\end{array}$ & $\begin{array}{c}\text { Control } \\
(\mathbf{n}=\mathbf{3 0})\end{array}$ & $\mathbf{p}$ \\
\cline { 1 - 3 } $\begin{array}{c}\text { Mean } \pm \\
\text { SD }\end{array}$ & $30.8 \pm 2.8$ & $30.2 \pm 2.5$ & $30 \pm 3$ & \multirow{2}{*}{0.46} \\
\cline { 1 - 2 } Range & $25-35.5$ & $24-35.5$ & $24-35.5$ & \\
\hline
\end{tabular}

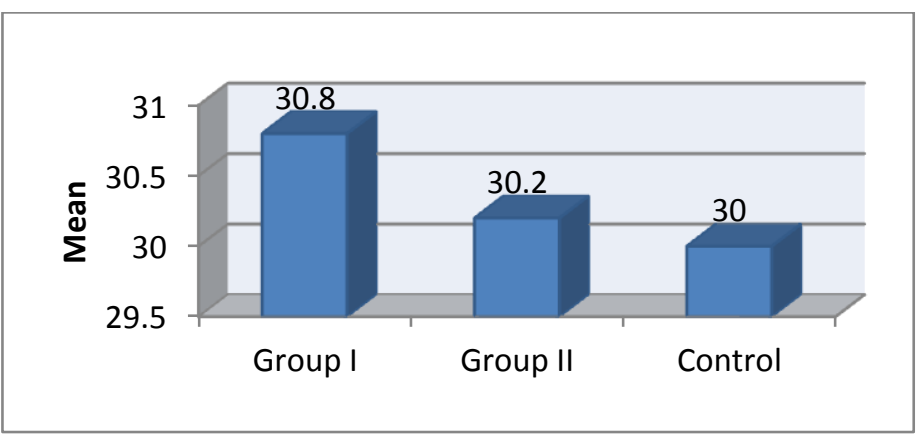

Figure (1): Body mass index in the studied groups

The changes in SOFA in the three groups are shown in table (1). There were statistically high significant differences between the three studied groups regarding $1^{\text {st }}, 2^{\text {nd }}, 3^{\text {rd }}, 4^{\text {th }}, 5^{\text {th }}$ and $7^{\text {th }}(\mathrm{p}<$ $0.001)$, a significant difference regarding $6^{\text {th }}(\mathrm{p}<$ $0.05)$ and a Nn-significant difference regarding after $7^{\text {th }}(\mathrm{p}>0.05)$. 
Table (3): SOFA changes

\begin{tabular}{|l|c|c|c|c|}
\hline & Group I & Group II & Group III & $\mathbf{p}$ \\
\hline $\mathbf{1}^{\text {st }}$ & $11.5 \pm 1.99$ & $14.1 \pm 37$ & $115.5 \pm 2.5$ & $\begin{array}{c}<\mathbf{0 . 0 0 1} \\
(\mathbf{H S})\end{array}$ \\
\hline $\mathbf{2}^{\text {nd }}$ & $9.5 \pm 2.2$ & $12.5 \pm 3.5$ & $13.9 \pm 3.1$ & $\begin{array}{c}<\mathbf{0 . 0 0 1} \\
(\mathbf{H S})\end{array}$ \\
\hline $\mathbf{3}^{\text {rd }}$ & $8 \pm 3$ & $11.1 \pm 3.9$ & $12.4 \pm 3.8$ & $\begin{array}{c}<\mathbf{0 . 0 0 1} \\
(\mathbf{H S})\end{array}$ \\
\hline $\mathbf{4}^{\text {th }}$ & $5.9 \pm 3.5$ & $9.2 \pm 4.3$ & $11.6 \pm 5.1$ & $\begin{array}{c}<\mathbf{0 . 0 0 1} \\
(\mathbf{H S})\end{array}$ \\
\hline $\mathbf{5}^{\text {th }}$ & $4.9 \pm 3.6$ & $7.9 \pm 5.2$ & $10.7 \pm 6.2$ & $\begin{array}{c}<\mathbf{0 . 0 0 1} \\
(\mathbf{H S})\end{array}$ \\
\hline $\mathbf{6}^{\text {th }}$ & $4.2 \pm 5.4$ & $6.8 \pm 5.1$ & $9.9 \pm 7.1$ & $\begin{array}{c}\mathbf{0 . 0 0 4} \\
(\mathbf{S})\end{array}$ \\
\hline $7^{\text {th }}$ & $4.2 \pm 5.4$ & $4.9 \pm 3.8$ & $10.2 \pm 7.1$ & $\begin{array}{c}<\mathbf{0 . 0 0 1} \\
(\mathbf{H S})\end{array}$ \\
\hline $\mathbf{A f t e r}^{\text {th }}$ & $4.2 \pm 3.4$ & $3.8 \pm 1.1$ & $5.3 \pm 1.1$ & $\begin{array}{c}0.09 \\
(\mathrm{NS})\end{array}$ \\
\hline
\end{tabular}

Table (3) showed statistically significant differences between the three studied groups regarding mortality and length of stay in intensive care unit $(\mathrm{p}<0.05)$ and a high significant difference regarding duration of vasopressors $(p<$ 0.001).

Table (4): Outcome and treatment variables

\begin{tabular}{|l|c|c|c|c|c|c|c|}
\hline \multirow{2}{*}{} & \multicolumn{2}{|c|}{$\begin{array}{c}\text { Group I } \\
(\mathbf{n}=\mathbf{3 0})\end{array}$} & \multicolumn{2}{|c|}{$\begin{array}{c}\text { Group II } \\
(\mathbf{n}=\mathbf{3 0})\end{array}$} & \multicolumn{2}{c|}{$\begin{array}{c}\text { Control } \\
(\mathbf{n = 3 0})\end{array}$} & \multirow{2}{*}{$\mathbf{p}$} \\
\cline { 2 - 7 } & $\mathbf{N}$ & $\%$ & $\mathbf{N}$ & $\%$ & $\mathbf{N}$ & $\%$ & \\
\hline Mortality & 4 & 13.3 & 8 & 26.7 & 14 & 46.7 & $\begin{array}{c}\mathbf{0 . 0 1 6} \\
(\mathbf{S})\end{array}$ \\
\hline ICU (LOS) & $8 \pm 1.8$ & $9.4 \pm 1.5$ & $9.7 \pm 1.9$ & $\begin{array}{c}\mathbf{0 . 0 1} \\
(\mathbf{S})\end{array}$ \\
\hline $\begin{array}{l}\text { Duration of } \\
\text { vasopressors }\end{array}$ & $18.9 \pm 8.7$ & $28.2 \pm 9.8$ & $52.2 \pm 20.8$ & $\begin{array}{c}\mathbf{0 . 0 0 1} \\
(\mathbf{H S})\end{array}$ \\
\hline
\end{tabular}

\section{Conclusion}

The main causes of ICU admission were respiratory distress and respiratory failure followed by septic shock. Most of the cases were suffering from one or more system failure especially circulatory failure; this contributes to the high mortality rate in our cases.

We suggested that the early use of intravenous vitamin $\mathrm{C}$ may prove to be effective in preventing progressive organ dysfunction including acute kidney injury and reducing the mortality of patients with severe sepsis and septic shock. This inexpensive and readily available intervention has the potential to reduce the global mortality from sepsis.

\section{Recommendations}

$\diamond$ The number of patients in this study is small, so studies on large numbers of patients might have an effect on the different variables.

$\diamond$ Additional studies are required to confirm our preliminary findings.

\section{References}

1. Singer, M., et al., The third international consensus definitions for sepsis and septic shock (sepsis-3). Jama, 2016. 315(8): p. 801-810.

2. Zabet, Mohadeseh Hosseini, et al. "Effect of high-dose Ascorbic acid on vasopressor's requirement in septic shock." Journal of research in pharmacy practice 5.2 (2016): 94.

3. Dellinger, R. Phillip, et al. "Surviving Sepsis Campaign: international guidelines for management of severe sepsis and septic shock, 2012." Intensive care medicine 39.2 (2013): 165-228.

4. Berger, Mette M. "Vitamin C requirements in parenteral nutrition." Gastroenterology 137.5 (2009): S70-S78.

5. Johnston, CAROL S., FRANCENE M. Steinberg, and ROBERT B. Rucker. "Ascorbic acid." Handbook of vitamins 4 (2007): 490-510.

6. Honore, Patrick M., et al. "Adjuvant vitamin $\mathrm{C}$ treatment in sepsis-how many oranges a day keep (vasopressordependent) septic shock away?." Journal of thoracic disease 8.9 (2016): E993. 